\title{
Epidemiology and Outcome of Ventilator-Associated Pneumonia in a Heterogeneous ICU Population in Qatar
}

\author{
Husain Shabbir Ali, ${ }^{1}$ Fahmi Yousef Khan, ${ }^{2}$ Saibu George, ${ }^{1}$ \\ Nissar Shaikh, ${ }^{3}$ and Jameela Al-Ajmi ${ }^{4}$ \\ ${ }^{1}$ Department of Medical ICU, Hamad General Hospital, P.O. Box 3050, Doha, Qatar \\ ${ }^{2}$ Department of Internal Medicine, Hamad General Hospital, P.O. Box 3050, Doha, Qatar \\ ${ }^{3}$ Department of Surgical ICU, Hamad General Hospital, P.O. Box 3050, Doha, Qatar \\ ${ }^{4}$ Department of Infectious Disease, Hamad General Hospital, P.O. Box 3050, Doha, Qatar \\ Correspondence should be addressed to Husain Shabbir Ali; drhusainali@gmail.com
}

Received 9 March 2016; Revised 30 April 2016; Accepted 19 May 2016

Academic Editor: Saad Nseir

Copyright (C) 2016 Husain Shabbir Ali et al. This is an open access article distributed under the Creative Commons Attribution License, which permits unrestricted use, distribution, and reproduction in any medium, provided the original work is properly cited.

\begin{abstract}
Objective. The purpose of this study is to collect data on epidemiology, microbiology, and outcome of VAP in our ICUs for reevaluation of the therapeutic strategies. Methods. This retrospective study involved all adult patients, 15 years of age or older, diagnosed with VAP in multidisciplinary ICUs at Hamad General Hospital between January 2010 and December 2012. Results. A total of 106 patients were enrolled. The mean incidence of VAP was 5.0 per 1000 ventilator-days. It was predominant among younger age group ( $<60$ years), male patients $(80.2 \%)$, and trauma ICU admissions $(49.0 \%)$. The most common comorbidity was hypertension (34\%) and polytrauma (36.8\%) was the most frequent admission diagnosis. 30-day mortality was $23.6 \%$ and it was significantly higher in $\geq 60$ years age group, female gender, patients with diabetes mellitus, hypertension, chronic respiratory disease, $\geq 1$ comorbidity, and poor functional status, smokers, medical and surgical ICU admissions, and patients with previous stay in medical/surgical wards, inappropriate empirical therapy, and admission diagnosis of respiratory failure. Gram-negative bacilli were the most frequent respiratory specimen isolates, Pseudomonas spp. being the most common. Majority of our Acinetobacter isolates were multidrug resistant. Conclusion. The incidence of VAP in our ICUs was low. Higher mortality rates were observed in certain subgroup of patients. Resistance to commonly used antimicrobials is likely to require reevaluation of the therapeutic strategies at our institution.
\end{abstract}

\section{Introduction}

Despite advances in preventive strategies, diagnostic techniques, and treatment modalities, ventilator-associated pneumonia (VAP) remains the most common infectious complication among patients admitted in intensive care units (ICUs). It results in high morbidity and mortality, prolonged lengths, and increased cost of hospitalization. The incidence of VAP varies widely in different studies depending on the diagnostic criteria used, type of ICU, and patient population. Moreover, the causative organisms vary according to the patients' demographics in the ICU, the duration of hospital/ICU stay, and the antibiotic policy of the institution [1]. Therefore, incidence of VAP and the associated microbial flora needs to be studied in local setting so as to allow more effective utilization of antimicrobial agents [2]. This prompted us to conduct a study, to describe the epidemiology, causative organisms, and outcome of VAP in a heterogeneous ICU population at a tertiary care center in Doha, State of Qatar, from January 2010 to December 2012.

\section{Materials and Methods}

2.1. Study Design and Setting. This retrospective study included all adult patients (15 years of age or older) clinically diagnosed with VAP in multidisciplinary ICUs at Hamad General Hospital, Qatar, between January 2010 and December 2012. Hamad General Hospital is a 603-bed tertiary care center 
that covers all specialties except for haematology-oncology, cardiology, and obstetrics. It has been Joint Commission International (JCI) accredited since 2006 and is the first hospital system in the region to achieve institutional accreditation from the Accreditation Council for Graduate Medical Education-International (ACGME-I). There are three adult ICUs in Hamad General Hospital, namely, medical ICU (MICU) with 22 beds, surgical ICU (SICU) with 12 beds, and trauma ICU (TICU) with 15 beds.

2.2. Definitions. Ventilator-associated pneumonia (VAP) was defined as per Center of Disease Control (CDC) as a pneumonia that occurs in a patient who has been intubated and ventilated for two or more calendar days on the date of the event. Clinical diagnosis of pneumonia was defined as the presence of a new or progressive pulmonary infiltrates or consolidation or cavitation in chest radiography, associated with at least two of the following criteria: body temperature of $>38^{\circ} \mathrm{C}$ or $<36^{\circ} \mathrm{C}$ with no other known cause, leucocytes count $<4000 / \mathrm{mm}^{3}$ or $>12000 / \mathrm{mm}^{3}$, and purulent tracheal secretion or a change in characteristics of an existing secretion [3]. All patients clinically diagnosed with VAP had respiratory specimen collected for Gram stain and culture-sensitivity, which was either deep tracheal aspirate or bronchoalveolar lavage (BAL).

VAP rates were described in accordance with the standard established by the National Control System of Nosocomial Infection of the Centers for Disease Control and Prevention (rate $=$ number of VAP cases/1000 mechanical ventilatordays) [4]. Comorbidities were defined by case records of patients. Clinical severity was assessed by Sequential Organ Failure Assessment (SOFA) score [5, 6].

The following pathogens were considered as MDR (multidrug resistant): methicillin-resistant Staphylococcus aureus (MRSA), extended-spectrum $\beta$-lactamase producing Gramnegative Enterobacteriaceae (ESBL), Pseudomonas aeruginosa, and other nonfermenting organisms (Acinetobacter baumannii, Stenotrophomonas maltophilia) resistant to three or more of the following antibiotic classes: antipseudomonal cephalosporins or penicillins, carbapenems, fluoroquinolones, and aminoglycosides [7]. Empirical antimicrobial therapy was considered as appropriate when initiated no later than 48 hours after VAP diagnosis and when it included at least one antimicrobial agent to which the etiological agent was described as susceptible in the antibiogram result [8].

2.3. Source of Information and Data Collection. Cases were identified by Infection Control Team at Hamad General Hospital based on the above diagnostic criteria. This was followed by retrospective chart review. Data were collected on a special form which included patient demographics, clinical characteristics, laboratory results, and outcome (30day mortality).

2.4. Data Analysis. Descriptive statistics in the form of mean, standard deviation for interval variables, and frequency with percentages for categorical variables were used. One-way ANOVA was performed to see significant mean differences among ICU groups and chi-square tests were performed to

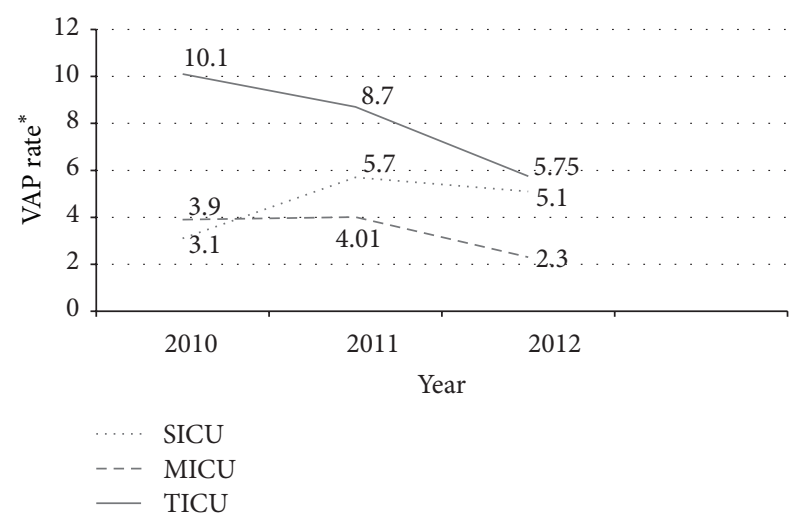

FIGURE 1: Mean ventilator-associated pneumonia (VAP) rates in SICU, MICU, and TICU during study period. VAP rate ${ }^{*}=$ (number of ventilator-associated pneumonias/number of ventilator-days) $\times$ 1000 .

see significant association between ICU groups and other categorical variables. $p$ value 0.05 with two-tailed test was considered statistically significant. Data analysis was performed with SPSS software (v 21.0; IBM Corp., Armonk, NY, USA).

\section{Results}

Over the 3-year study period (January 2010 to December 2012), 126 episodes of VAP were reported in three ICUs. For determination of incidence all episodes of VAP were considered. For collection of demographic, microbiological, and outcome data twenty patients were excluded: one because of age less than 15 years and the other due to having a second episode of VAP and another eighteen due to incomplete records. The remaining 106 patients with complete records had their charts reviewed.

3.1. Incidence and Demographics. The overall mean incidence rate of VAP was 5.0 per 1000 ventilator-days and the cumulative VAP rates in each year were 5.42 per 1000 ventilator-days in 2010, 5.91 per 1000 ventilator-days in 2011, and 3.88 per 1000 ventilator-days in 2012. VAP rate ranged from as high as 10.1 per 1000 ventilator-days in TICU during 2010 to as low as 2.3 per 1000 ventilator-days in MICU during 2012. Figure 1 shows comparison between the mean VAP rates in MICU, SICU, and TICU during the 3-year study period.

The mean age of patients was $46.6 \pm 18.6$ years (range 16-90 years) and $73.6 \%$ patients (78/106) were less than 60 years old. There were $80.2 \%$ (85/106) males and 29.2\% (31/106) Qatari patients (Table 1).

3.2. Comorbidities and Associated Conditions. The most frequent comorbidity was hypertension $(36 / 106,34.0 \%)$, and the most frequent associated condition was smoking, while the most frequent ICU admission diagnosis was polytrauma (39/106, 36.8\%). The mean Sequential Organ Failure Assessment (SOFA) score on admission was $6.5 \pm 3.4$ (range 115); it was highest among patients admitted to MICU. The duration of mechanical ventilation before diagnosis of VAP 
TABLE 1: Clinical data of patients admitted with VAP.

\begin{tabular}{|c|c|c|c|c|}
\hline Characteristic & $\begin{array}{c}\text { MICU } \\
N=27(\%)\end{array}$ & $\begin{array}{c}\text { SICU } \\
N=27(\%)\end{array}$ & $\begin{array}{c}\text { TICU } \\
N=52(\%)\end{array}$ & $\begin{array}{c}\text { Overall } \\
N=106(\%)\end{array}$ \\
\hline Age (mean \pm SD) (years) & $57.9 \pm 16.2$ & $53.1 \pm 15.9$ & $37.3 \pm 16.4$ & $46.6 \pm 18.6$ \\
\hline \multicolumn{5}{|l|}{ Gender } \\
\hline Male & $17(63)$ & $21(77.8)$ & $47(90.4)$ & $85(80.2)$ \\
\hline Female & $10(37)$ & $6(22.2)$ & $5(9.6)$ & $21(19.8)$ \\
\hline \multicolumn{5}{|l|}{ Ethnicity } \\
\hline Qatari & $10(37)$ & $6(22.2)$ & $15(28.8)$ & $31(29.2)$ \\
\hline African & $2(7.4)$ & $5(18.5)$ & $7(13.5)$ & $14(13.2)$ \\
\hline Indian subcontinent & $12(44.4)$ & $13(48.1)$ & $22(42.3)$ & $47(44.3)$ \\
\hline Southeast Asians & 0 & 0 & $5(9.6)$ & $5(4.7)$ \\
\hline Others & $3(11.2)$ & $3(11.2)$ & $3(5.8)$ & $9(8.5)$ \\
\hline \multicolumn{5}{|l|}{ Comorbidities } \\
\hline Diabetes mellitus & $12(44.4)$ & $11(40.7)$ & $7(13.5)$ & $30(28.3)$ \\
\hline Hypertension & $15(55.6)$ & $13(48.1)$ & $8(15.4)$ & $36(34)$ \\
\hline Cardiovascular disease & $6(22.2)$ & $6(22.2)$ & $3(5.8)$ & $15(14.2)$ \\
\hline Renal disease & $3(11.1)$ & $2(7.4)$ & $2(3.8)$ & $7(6.6)$ \\
\hline Neurological condition & $6(22.2)$ & $1(3.7)$ & 0 & $7(6.6)$ \\
\hline Respiratory disease & $5(18.5)$ & $3(11.1)$ & $2(3.8)$ & $10(9.4)$ \\
\hline Hepatic disease & $4(14.8)$ & $2(7.4)$ & $2(3.8)$ & $8(7.5)$ \\
\hline Malignancy & $1(3.7)$ & $3(11.1)$ & $1(1.9)$ & $5(4.7)$ \\
\hline Smoker & $8(29.6)$ & $9(33.3)$ & $3(5.8)$ & $20(18.9)$ \\
\hline \multicolumn{5}{|l|}{ Functional status } \\
\hline Ambulatory & $20(74)$ & $25(92.6)$ & $52(100)$ & $97(91.5)$ \\
\hline Bed bound & $7(26)$ & $2(7.4)$ & 0 & $9(8.5)$ \\
\hline \multicolumn{5}{|l|}{ Source of admission } \\
\hline Emergency room & $10(37)$ & $11(40.7)$ & $48(92.3)$ & $69(65.1)$ \\
\hline Ward (medical/surgical) & $15(55.6)$ & $11(40.7)$ & 0 & $26(24.5)$ \\
\hline Operation room & 0 & $4(14.9)$ & 0 & $4(3.8)$ \\
\hline Other hospitals & $2(7.4)$ & $1(3.7)$ & $4(7.7)$ & $7(6.6)$ \\
\hline \multicolumn{5}{|l|}{ Admission diagnosis } \\
\hline Head trauma & 0 & 0 & $12(23.1)$ & $12(11.3)$ \\
\hline Polytrauma & 0 & 0 & $39(75)$ & $39(36.8)$ \\
\hline Respiratory failure & $11(40.7)$ & $3(11.1)$ & 0 & $14(13.2)$ \\
\hline Sepsis & $4(14.9)$ & $8(29.6)$ & 0 & $12(11.3)$ \\
\hline Neurological disease & $10(37)$ & $9(33.3)$ & $1(1.9)$ & $20(18.9)$ \\
\hline Cardiovascular disease & 0 & $2(7.4)$ & 0 & $2(1.9)$ \\
\hline Intra-abdominal disease & $1(3.7)$ & $4(14.8)$ & 0 & $5(4.7)$ \\
\hline Miscellaneous & $1(3.7)$ & $1(3.7)$ & 0 & $2(1.9)$ \\
\hline SOFA* $^{*}$ score $($ mean $\pm \mathrm{SD})$ & $7.8 \pm 3.0$ & $5.7 \pm 3.3$ & $6.2 \pm 3.4$ & $6.5 \pm 3.4$ \\
\hline $\begin{array}{l}\text { Duration of mechanical ventilation before } \\
\text { developing VAP (mean } \pm \text { SD) (days) }\end{array}$ & $17.0 \pm 11.9$ & $11.4 \pm 9.8$ & $9.5 \pm 6.8$ & $11.9 \pm 9.5$ \\
\hline Inappropriate antibiotic therapy & $10(37)$ & $8(29.6)$ & $5(9.6)$ & $23(21.7)$ \\
\hline
\end{tabular}

${ }^{*}$ SOFA: Sequential Organ Failure Assessment.

was $11.9 \pm 9.5$ days (range 2-46 days) and it was longest in patients admitted to medical ICU ( $p=0.003)$; refer to Table 1.
3.3. Microbial Pattern and Antimicrobial Susceptibility. Deep tracheal aspiration was done to collect respiratory sample in 96/106 (90.6\%) cases and BAL was done in the remaining 
$10 / 106(9.4 \%)$ cases. Single organism was isolated from respiratory specimen of 52/106 (49\%) patients and $\geq 2$ organisms isolated from another 52/106 (49\%) patients and cultures were negative in 2 patients. The most common isolate was Pseudomonas species (Table 2); 43/106 (40.6\%) patients had at least one organism which was MDR and 61/106 (57.5\%) had completely sensitive strains. Table 2 summarizes the antibiotic sensitivity pattern of the most frequent microorganisms isolated in this study.

3.4. Outcome and Comparison between Survivors and Nonsurvivors. The 30-day mortality in our study was 25/106 (23.6\%). Several variables were evaluated for association with clinical outcome, as presented in Table 3. Among patients who developed VAP, mortality was significantly higher in age group $\geq 60$ years $(p=0.001)$, female gender $(p=0.02)$, and those with $\geq 1$ comorbidity $(p=0.001)$; in patients with diabetes mellitus $(p=0.012)$, hypertension $(p=0.001)$, and preexisting respiratory disease $(p=0.004)$. It was also observed that smokers $(p=0.012)$, bed bound patients $(p=$ $0.018)$, MICU admissions ( $p=0.001)$, patients admitted from medical/surgical wards $(p=0.001)$, patients receiving inappropriate empirical therapy $(p=0.001)$, and those having admission diagnosis of respiratory failure $(p=0.001)$ had higher mortality. Mortality in patients with sensitive organisms was $16.4 \%$ and MDR organisms was $32.6 \%$ ( $p=$ $0.054)$. Patients with respiratory specimen isolates of single organism, $\geq 2$ organisms, and negative culture had mortality rates of $30.8 \%, 15.4 \%$, and $50 \%$, respectively. There was no significant relationship between specific microorganisms and mortality.

\section{Discussion}

Novelty of our work comes from being the first to study VAP in the State of Qatar. The mean VAP incidence in our study was 5.0 per 1000 ventilator-days, which falls below the rate of 8.8 per 1000 ventilator-days reported in European and South American ICUs [9] and is comparable to the incidence reported in other Gulf countries (4.8 per 1000 ventilatordays) [10]. The reason for our lower incidence rate is not clear. It could be due to involvement of young population with short period of ventilation or due to variability in the definition of VAP or it might reflect efficiency of the preventive strategies and critical care practices in our ICUs. VAP prevention bundle is one of the major strategies used at our institution for reducing the incidence of VAP. It comprises the following components: elevation of the head of the bed between 30 and 45 degrees, daily sedation interruption and assessment of readiness to extubate, use of subglottic suction endotracheal tubes, peptic ulcer disease prophylaxis, deep vein thrombosis prophylaxis, and oral care with chlorhexidine solution.

As noted in this series, the patients were younger (46.56 \pm 18.57 years) than those reported in a retrospective cohort study using data from a large US inpatient database $(61.7 \pm$ 19.2 years) [11]. Also they were younger than patients with ICU-acquired sepsis in the European SOAP study $(60.0 \pm 17.4$ years) [12]. The reason for this remains obscured and needs to be investigated. In agreement with many reports, our study showed male predominance $[8,11,13]$ which can be explained by the fact that Qatar and other Gulf countries have large working community composed mainly of males. Male sex is one of the nonmodifiable patient-related risk factors for the development of VAP [14].

A multicenter study from Greece, involving a mixed ICU population, has reported $45 \%$ of its VAP cases to have ICU admission due to trauma (multiple injury: 29\% and head injury: 16\%) [13] which coincides with our findings, where we had $49 \%$ of patients from TICU. Higher incidence of VAP has been reported in patients with neurocritical illness [15]. In our study, $18.9 \%(20 / 106)$ of the VAP cases were initially admitted to ICU due to neurological disease. 30-day mortality in this subgroup was $40 \%(8 / 20)$. The SOFA score of our VAP patients on ICU admission $(6.46 \pm 3.36)$ was lower than that reported in the PneumA trial $(7.3 \pm 4$ and $7.4 \pm 4$ in the 8-day and 15-day antibiotic regimen, resp.) [16]. This could be related to the difference in the indication for initial ICU admission in both studies.

In our population, Gram-negative bacteria were the most common pathogens causing VAP with Pseudomonas aeruginosa being the most frequent isolate (Table 2). Similar findings were reported by many authors [1, 17]. Most of the Acinetobacter baumannii isolates were resistant to piperacillin/tazobactam and carbapenems, which raises doubts about the ongoing efficacy of these agents in the empirical treatment of VAP at our hospital.

Mortality associated with VAP has varied in different studies depending on the term used (in-hospital mortality versus attributable mortality versus 30-day mortality), institution, and study population. The 30-day mortality in our study was $23.6 \%$, which falls within the range of $20 \%-75 \%$ described in recent studies [1]. In our population, mortality was higher in the elderly subgroup (age $\geq 60$ years) as shown in Table 3 and is consistent with recent reports [18]. As per our observation, females developed less VAP but experienced increased mortality ( $42.9 \%$ versus $18.8 \%, p=0.02)$ and this confirms the results from previous studies [19]. Resende and coworkers have emphasized on the fact that the presence of comorbidities has significant impact on the outcome of patients with VAP [8]. Similar results are seen in our analysis where preexisting hypertension, diabetes mellitus, chronic respiratory disease, presence of $\geq 1$ comorbid condition, and poor functional status have been associated with increased mortality (Table 3 ). In agreement with many reports, our data showed a significant association between inappropriate empirical therapy and increased mortality [2, 5, 20, 21]. This highlights the importance of local studies in providing information about the most likely causative organisms and their resistance patterns to assist clinicians in selecting appropriate empirical treatment, if VAP is suspected.

This study has several limitations. Firstly, due to its retrospective design, there was incomplete data for some factors related to mortality and compliance to VAP prevention bundles. Secondly, the study was conducted in one hospital, thereby limiting the generalization of these results to other institutions in Qatar. Thirdly, the diagnostic criteria for VAP which we used might differ from those used 


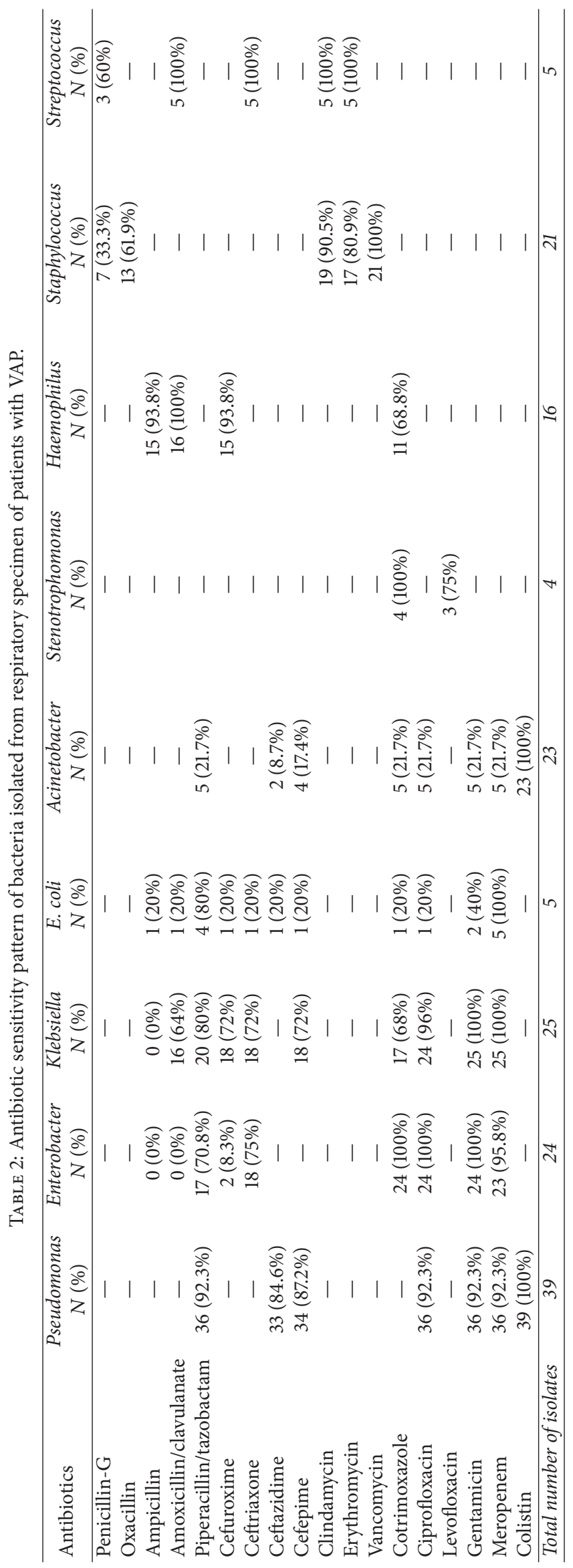


TABLE 3: Association of epidemiological and clinical variables with outcome $(N=106)$.

\begin{tabular}{|c|c|c|c|}
\hline Variable & Survivors & Nonsurvivors & $p$ value \\
\hline \multicolumn{4}{|l|}{ Age } \\
\hline Mean \pm SD (years) & $43.1 \pm 17.8$ & $57.8 \pm 16.8$ & 0.001 \\
\hline$<60$ years & $66(84.6 \%)$ & $12(15.4 \%)$ & \multirow{2}{*}{0.001} \\
\hline$\geq 60$ years & $15(53.6 \%)$ & $13(46.4 \%)$ & \\
\hline \multicolumn{4}{|l|}{ Gender } \\
\hline Male & $69(81.2 \%)$ & $16(18.8 \%)$ & \multirow{2}{*}{0.02} \\
\hline Female & $12(57.1 \%)$ & $9(42.9 \%)$ & \\
\hline \multicolumn{4}{|l|}{ Ethnicity } \\
\hline Qatari & $20(64.5 \%)$ & $11(35.5 \%)$ & \multirow{5}{*}{0.338} \\
\hline African & $11(78.6 \%)$ & $3(21.4 \%)$ & \\
\hline Indian subcontinent & $38(80.9 \%)$ & $9(19.1 \%)$ & \\
\hline Southeast Asians & $5(100 \%)$ & $0(0 \%)$ & \\
\hline Others & $7(77.8 \%)$ & $2(22.2 \%)$ & \\
\hline \multicolumn{4}{|l|}{ Number of comorbidities } \\
\hline 0 & $53(91.4 \%)$ & $5(8.6 \%)$ & \multirow{3}{*}{0.001} \\
\hline 1 & $7(53.8 \%)$ & $6(46.2 \%)$ & \\
\hline$\geq 2$ & $21(60 \%)$ & $14(40 \%)$ & \\
\hline \multicolumn{4}{|l|}{ Comorbidities } \\
\hline Diabetes mellitus & $18(60 \%)$ & $12(40 \%)$ & \multirow{2}{*}{0.012} \\
\hline Without diabetes mellitus & $63(82.9 \%)$ & $13(17.1 \%)$ & \\
\hline Hypertension & $20(55.6 \%)$ & $16(44.4 \%)$ & \multirow{2}{*}{0.001} \\
\hline Without hypertension & $61(87.1 \%)$ & $9(12.9 \%)$ & \\
\hline Cardiovascular disease & $9(60 \%)$ & $6(40 \%)$ & \multirow{2}{*}{0.106} \\
\hline Without cardiovascular disease & $72(79.1 \%)$ & $19(20.9 \%)$ & \\
\hline Renal disease & $4(57.1 \%)$ & $3(42.9 \%)$ & \multirow{2}{*}{0.214} \\
\hline Without renal disease & $77(77.8 \%)$ & $22(22.2 \%)$ & \\
\hline Neurological condition & $4(57.1 \%)$ & $3(42.9 \%)$ & \multirow{2}{*}{0.214} \\
\hline Without neurological condition & $77(77.8 \%)$ & $22(22.2 \%)$ & \\
\hline Respiratory disease & $4(40 \%)$ & $6(60 \%)$ & \multirow{2}{*}{0.004} \\
\hline Without respiratory disease & $77(80.2 \%)$ & $19(19.8 \%)$ & \\
\hline Hepatic disease & $4(50 \%)$ & $4(50 \%)$ & \multirow{2}{*}{0.067} \\
\hline Without hepatic disease & $77(78.6 \%)$ & $21(21.4 \%)$ & \\
\hline Malignancy & $4(80 \%)$ & $1(20 \%)$ & \multirow{2}{*}{0.847} \\
\hline Without malignancy & $77(76.2 \%)$ & $24(23.8 \%)$ & \\
\hline \multicolumn{4}{|l|}{ Associated factor } \\
\hline Smoker & $11(55 \%)$ & $9(45 \%)$ & \multirow{2}{*}{0.012} \\
\hline Nonsmoker & $70(81.4 \%)$ & $16(18.6 \%)$ & \\
\hline \multicolumn{4}{|l|}{ Functional status } \\
\hline Ambulatory & $77(79.4 \%)$ & $20(20.6 \%)$ & \multirow{2}{*}{0.018} \\
\hline Bed bound & $4(44.4 \%)$ & $5(55.6 \%)$ & \\
\hline \multicolumn{4}{|l|}{ Admitting ICU } \\
\hline Medical ICU & $13(48.1 \%)$ & $14(51.9 \%)$ & \multirow{3}{*}{0.001} \\
\hline Surgical ICU & $19(70.4 \%)$ & $8(29.6 \%)$ & \\
\hline Trauma ICU & $49(94.2 \%)$ & $3(5.8 \%)$ & \\
\hline
\end{tabular}


TABLE 3: Continued.

\begin{tabular}{|c|c|c|c|}
\hline Variable & Survivors & Nonsurvivors & $p$ value \\
\hline \multicolumn{4}{|l|}{ Source of admission } \\
\hline Emergency room & $61(88.4 \%)$ & $8(11.6 \%)$ & \multirow{4}{*}{0.001} \\
\hline Ward (medical/surgical) & $12(46.2 \%)$ & $14(53.8 \%)$ & \\
\hline Operating room & $2(50 \%)$ & $2(50 \%)$ & \\
\hline Other hospitals & $6(85.7 \%)$ & $1(14.3 \%)$ & \\
\hline \multicolumn{4}{|l|}{ Admission diagnosis } \\
\hline Head trauma & $12(100 \%)$ & $0(0 \%)$ & \multirow{8}{*}{0.001} \\
\hline Polytrauma & $36(92.3 \%)$ & $3(7.7 \%)$ & \\
\hline Respiratory failure & $6(42.9 \%)$ & $8(57.1 \%)$ & \\
\hline Sepsis & $8(66.7 \%)$ & $4(33.3 \%)$ & \\
\hline Neurological disease & $12(60 \%)$ & $8(40 \%)$ & \\
\hline Cardiovascular disease & $1(50 \%)$ & $1(50 \%)$ & \\
\hline Intra-abdominal disease & $5(100 \%)$ & $0(0 \%)$ & \\
\hline Miscellaneous & $1(50 \%)$ & $1(50 \%)$ & \\
\hline SOFA score on admission $($ mean \pm SD) & $6.2 \pm 3.2$ & $7.5 \pm 3.6$ & 0.08 \\
\hline $\begin{array}{l}\text { Duration of mechanical ventilation before } \\
\text { developing VAP (days) (mean } \pm \text { SD) }\end{array}$ & $11.9 \pm 9.7$ & $12.0 \pm 9.1$ & 0.95 \\
\hline \multicolumn{4}{|l|}{ Onset of VAP } \\
\hline Early ( $\leq 4$ days) & $16(80 \%)$ & $4(20 \%)$ & \multirow{2}{*}{0.675} \\
\hline Late ( $>4$ days) & $65(75.6 \%)$ & $21(24.4 \%)$ & \\
\hline Inappropriate antibiotic therapy & $9(11.3 \%)$ & $14(58.3 \%)$ & 0.001 \\
\hline
\end{tabular}

by other hospitals. This may lead to overestimation or underestimation of the incidence and not allow comparison with other institutions. Despite these limitations, this study is the first step in highlighting the problem of VAP in the State of Qatar, and it has implications for future work.

\section{Conclusion}

The overall incidence of VAP in our ICUs was low. Higher mortality rates were associated with increasing age, female gender, presence of comorbidities, admission to medical ICU, patients admittance from wards, primary diagnosis of respiratory failure, and inappropriate empirical therapy. Resistance to piperacillin/tazobactam and carbapenems is likely to require reevaluation of the therapeutic strategies used at Hamad General Hospital. We recommend conducting prospective multicenter studies to know local risk factors and patterns of pathogens causing VAP to assist in making appropriate preventive, diagnostic, and therapeutic plans to reduce their incidence and improve outcomes.

\section{Ethical Approval}

Ethical approval was obtained from the medical research committee at Hamad Medical Corporation. As the study was retrospective, a waiver of informed consent was obtained from the research committee.

\section{Disclosure}

This study was presented as a poster and research snap shot presentation at SCCM's 45th Critical Care Congress, February 2016, in Orlando, USA.

\section{Competing Interests}

All the authors declare that there were no known competing interests associated with this publication and there has been no financial support for this work that could have influenced its outcome.

\section{References}

[1] E. Alp and A. Voss, "Ventilator associated pneumonia and infection control," Annals of Clinical Microbiology and Antimicrobials, vol. 5, article 7, 2006.

[2] P. Rakshit, V. S. Nagar, and A. K. Deshpande, "Incidence, clinical outcome, and risk stratification of ventilator-associated pneumonia-a prospective cohort study," Indian Journal of Critical Care Medicine, vol. 9, no. 4, pp. 211-216, 2005.

[3] W. G. Johanson Jr., A. K. Pierce, J. P. Sanford, and G. D. Thomas, "Nosocomial respiratory infections with gram-negative bacilli: the significance of colonization of the respiratory tract," Annals of Internal Medicine, vol. 77, no. 5, pp. 701-706, 1972.

[4] J.-F. Timsit, S. Chevret, J. Valcke et al., "Mortality of nosocomial pneumonia in ventilated patients: influence of diagnostic tools," American Journal of Respiratory and Critical Care Medicine, vol. 154, no. 1, pp. 116-123, 1996. 
[5] A. Torres and J. Carlet, "Ventilator-associated pneumonia. European Task Force on ventilator-associated pneumonia," European Respiratory Journal, vol. 17, no. 5, pp. 1034-1045, 2001.

[6] J.-L. Vincent, A. de Mendonça, F. Cantraine et al., "Use of the SOFA score to assess the incidence of organ dysfunction/failure in intensive care units: results of a multicenter, prospective study," Critical Care Medicine, vol. 26, no. 11, pp. 1793-1800, 1998.

[7] P. O. Depuydt, D. M. Vandijck, M. A. Bekaert et al., "Determinants and impact of multidrug antibiotic resistance in pathogens causing ventilator-associated-pneumonia," Critical Care, vol. 12, no. 6, article R142, 2008.

[8] M. M. Resende, S. G. Monteiro, B. Callegari, P. M. S. Figueiredo, C. R. A. V. Monteiro, and V. Monteiro-Neto, "Epidemiology and outcomes of ventilator-associated pneumonia in northern Brazil: an analytical descriptive prospective cohort study," $B M C$ Infectious Diseases, vol. 13, article 119, 2013.

[9] I. Martin-Loeches, P. Povoa, A. Rodríguez et al., "Incidence and prognosis of ventilator-associated tracheobronchitis (TAVeM): a multicentre, prospective, observational study," The Lancet Respiratory Medicine, vol. 3, no. 11, pp. 859-868, 2015.

[10] A. El-Saed, H. H. Balkhy, H. Alansari et al., "Rates of ventilatorassociated pneumonia in critical care units in three Arabian Gulf countries; six-year surveillance study," Antimicrobial Resistance and Infection Control, vol. 4, supplement 1, p. 245, 2015.

[11] J. Rello, D. A. Ollendorf, G. Oster et al., "Epidemiology and outcomes of ventilator-associated pneumonia in a large US database," Chest, vol. 122, no. 6, pp. 2115-2121, 2002.

[12] J.-L. Vincent, Y. Sakr, C. L. Sprung et al., "Sepsis in European intensive care units: results of the SOAP study," Critical Care Medicine, vol. 34, no. 2, pp. 344-353, 2006.

[13] E. Apostolopoulou, P. Bakakos, T. Katostaras, and L. Gregorakos, "Incidence and risk factors for ventilator-associated pneumonia in 4 multidisciplinary intensive care units in Athens, Greece," Respiratory Care, vol. 48, no. 7, pp. 681-688, 2003.

[14] M. J. M. Bonten, M. H. Kollef, and J. B. Hall, "Risk factors for ventilator-associated pneumonia: from epidemiology to patient management," Clinical Infectious Diseases, vol. 38, no. 8, pp. 1141-1149, 2004.

[15] M. Mehndiratta, R. Nayak, S. Ali, A. Sharma, and N. Gulati, "Ventilators in ICU: a boon or burden," Annals of Indian Academy of Neurology, vol. 19, no. 1, pp. 69-73, 2016.

[16] J. Chastre, M. Wolff, J.-Y. Fagon et al., "Comparison of 8 vs 15 days of antibiotic therapy for ventilator-associated pneumonia in adults: a randomized trial," The Journal of the American Medical Association, vol. 290, no. 19, pp. 2588-2598, 2003.

[17] Y. Arabi, N. Al-Shirawi, Z. Memish, and A. Anzueto, "Ventilator-associated pneumonia in adults in developing countries: a systematic review," International Journal of Infectious Diseases, vol. 12, no. 5, pp. 505-512, 2008.

[18] S. Blot, D. Koulenti, G. Dimopoulos et al., "Prevalence, risk factors, and mortality for ventilator-associated pneumonia in middle-aged, old, and very old critically ill patients," Critical Care Medicine, vol. 42, no. 3, pp. 601-609, 2014.

[19] J. P. Sharpe, L. J. Magnotti, J. A. Weinberg et al., "Gender disparity in ventilator-associated pneumonia following trauma: identifying risk factors for mortality," Journal of Trauma and Acute Care Surgery, vol. 77, no. 1, pp. 161-165, 2014.

[20] J. Inchai, C. Pothirat, C. Liwsrisakun, A. Deesomchok, W. Kositsakulchai, and N. Chalermpanchai, "Ventilator-associated pneumonia: epidemiology and prognostic indicators of 30-day mortality," Japanese Journal of Infectious Diseases, vol. 68, no. 3, pp. 181-186, 2015.

[21] C. M. Luna, P. Vujacich, M. S. Niederman et al., "Impact of BAL data on the therapy and outcome of ventilator-associated pneumonia," Chest, vol. 111, no. 3, pp. 676-685, 1997. 


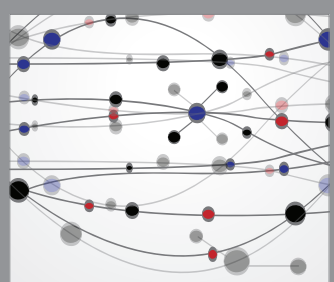

The Scientific World Journal
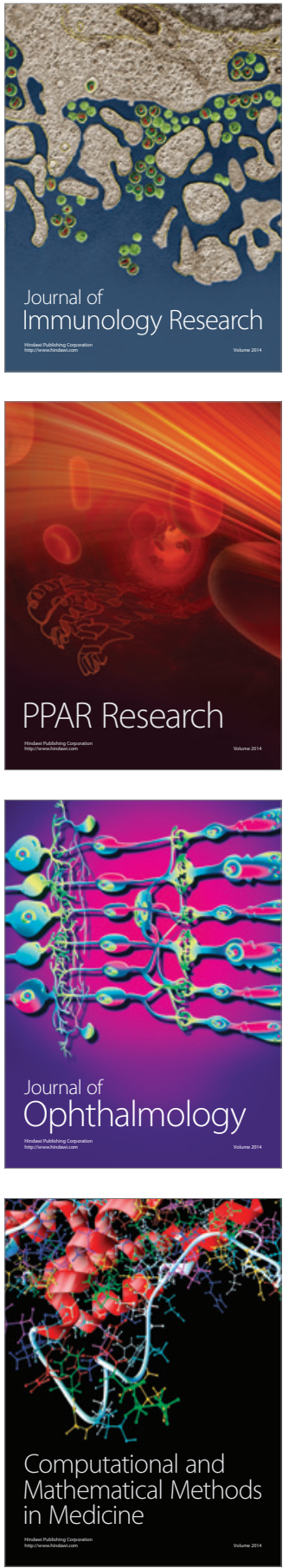

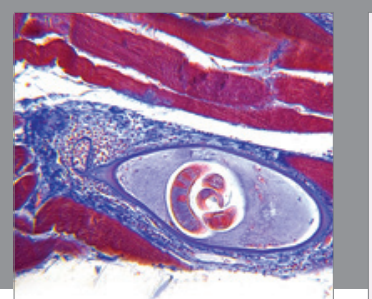

Gastroenterology Research and Practice

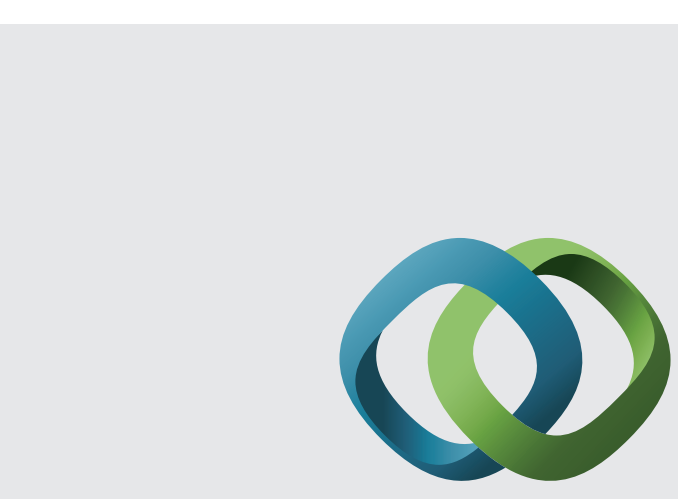

\section{Hindawi}

Submit your manuscripts at

http://www.hindawi.com
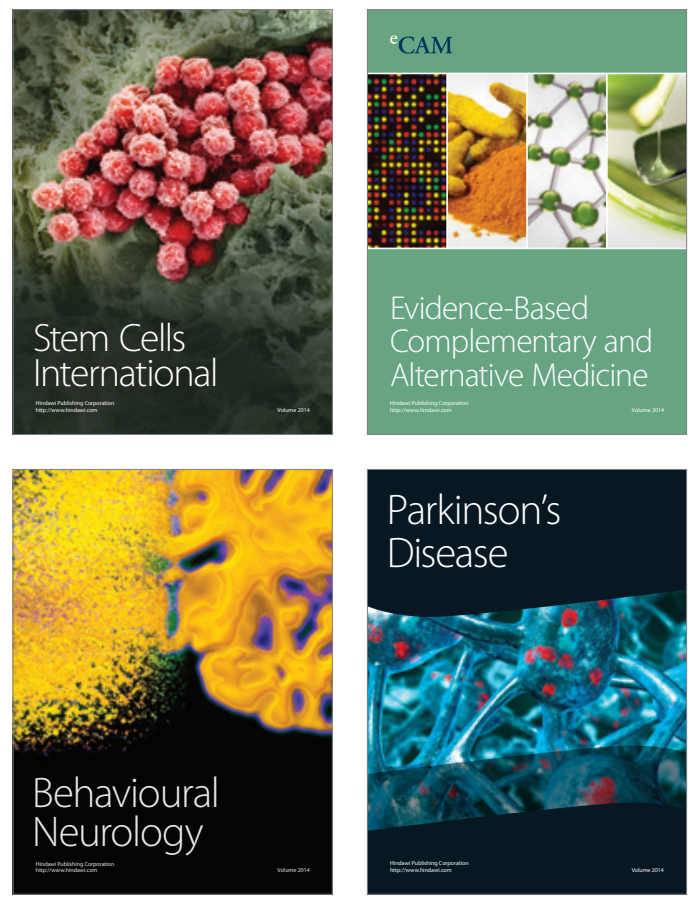
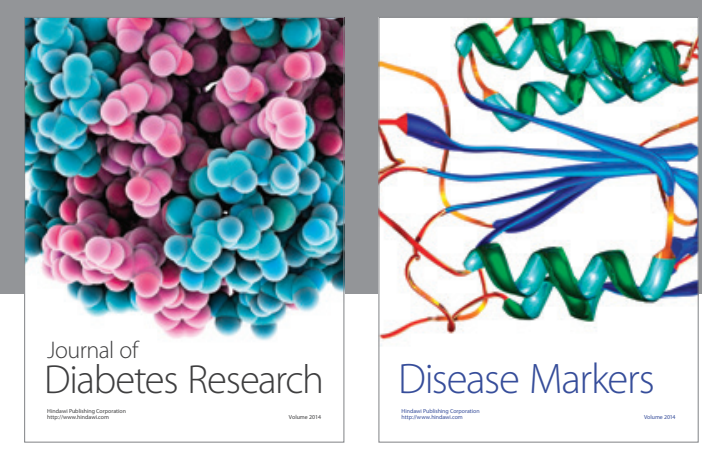

Disease Markers
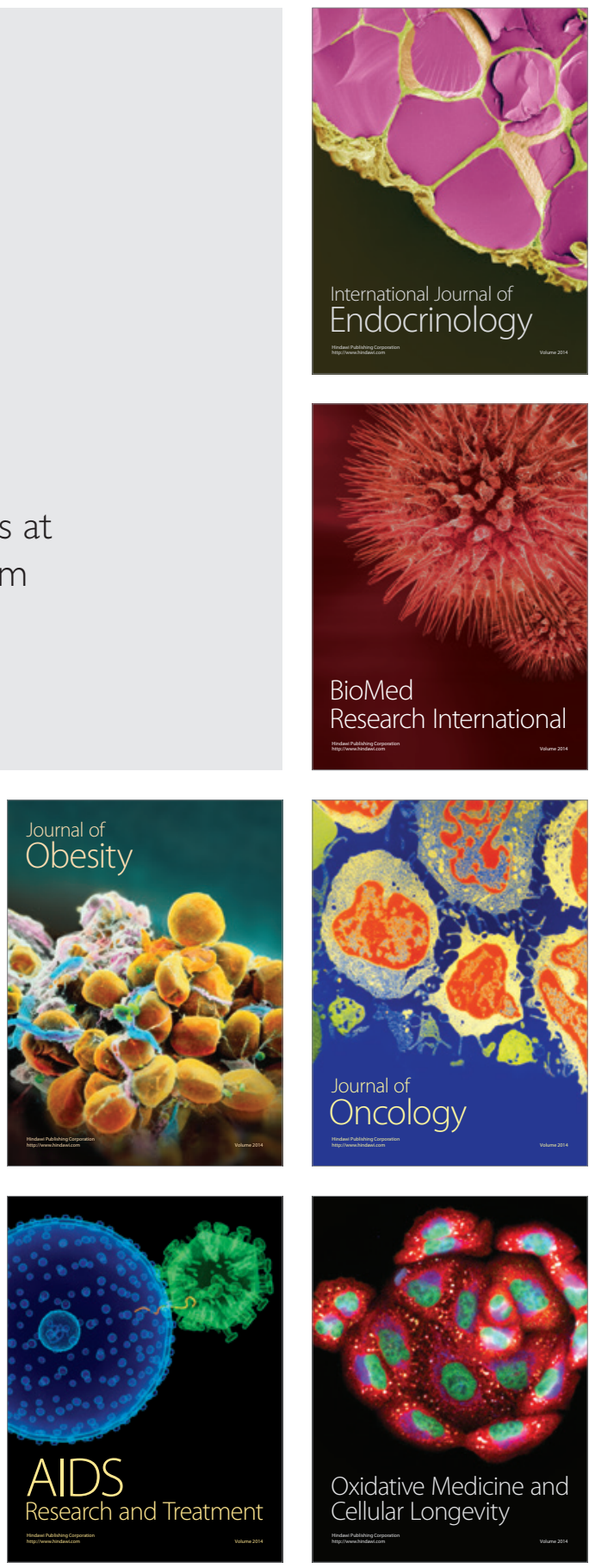